twice as heavy as a measure of coals; it follows that, ten pounds of coals are required to calcine 100 of carbonate, or one pound coals to 4.4 pounds carbonic acid; but as eighty-four pounds of the live coals would heat and evaporate twelve cubic feet of water, one pound of coals would heat and evaporate nine pounds of water. We thus find by rather a rough process, but from facts correct enough for general reasoning, because derived from operations conducted on the large scale, that the latent heat in carbonic acid gas, is about double the latent heat of steam.

If 37 parts hydrate of lime is placed in contact with 22 carbonic acid, the nine parts of water in the hydrate will be all expelled, and the carbonic gas combining in a solid form with the lime gives out its latent heat, which being taken up by the water, it escapes in the form of vapour, or steam of superior elasticity to the atmospheric pressure, although its temperature is insensible, this very curious or rather wonderful fact, and others, bitherto, I believe, wholly unnoticed, we shall see amply verified when we examine the properties of cements.

FOI THE JOURNAL OF THE FRANKRIN INSTITUTE.

\title{
On the Production and Manufacture of Salad or Table Oil in the United States.
}

The following remarks are intended to apply to that strip of the United States, which is comprehended between the latitudes of Cape Hatteras and Boston bay, extending westward.

Although there is no part of this extensive region in which the olive tree could be cultivated, except when protected by the green house, and thereforc, the inhabitants are denied the advantages of this useful tree, it does not follow, that nature has denied them the means of procuring an excellent and pleasant substitute for olive oil, and one that could be brought into market at a moderate cost. Between them and this enjoyment, ignorance is at present a barrier, and in this case, as in many others, this is strength. ened in its result, by prejudice.

In French Flanders, the farmers cultivate in large fields, and to a great extent the White Poppy. The seeds of this plant are collected and bruised in some way, and an oil expressed from them, which in all respects resembles olive oil, and is the source from whence is derived a large proportion of what is consumed in Paris. The poppy oil so much resembles olive oil, that strangers who visit Paris take it for that oil. These are facts as regards the consumption.

Of the state of this important branch of husbandry and manufacture, we the people of the United States know nothing. How is it cultivated, the seed collected, the oil preserved? Does the land require to be sown every year, or does it seed itself? What sort of a mill does it require? What is the product in oil, or in profit? In short, we have every thing to learn, except that, incidentally we have heard that fifty pounds of beet cake, after the sugar maker has got what he wants out of it, and ten pounds of poppy seed after the oil maker has done with it, will keep ten sheep a day and fatten them.

We know that since the article on beet sugar appeared in the Journal of the Franklin Institute, requesting those who knew any thing of the subject to favour the editor of the Journal or the public with information, a well 
qualified agent has been sent to Europe to acquaint himself with the whole agricultural and manufacturing business that produces sugar.

On the present occasion, we invite the patrons of our country's industry and resources, to communicate for publication, what they know on the above interesting branch of French husbandry, \&c. And we therefore request the wealthy and patriotic, to consider whether the case of oil does not resemble that of the sugar from the beet, and whether the best course would not be to adopt a plan similar to that which the friends of beet sugar have chosen.

The time will come when American parents will send their sons to Europe and to other foreign places, to learn the manufacture of beet sugar, of oil, and such other branches of the arts not possessed by us, in the same manner and with better reason that they now do to have them Iearn medicine and surgery:

June 4, 1836.

J. R.

\section{Civil Engineering.}

Some suggestions on the Location and Grading of Rail Roads. By Thomas Earle.

In the location and grading of rail roads, it is usual to reduce the road in sill parts, as near to a level as possible, and in effecting this object, to make many curvatures, some of them of small ralius. Thus, a very considerable increase of expenditure and of distance is occasioned, which appears to me inexpedient.

It is true, that if a rail road could be made perfectly level, or very nearly so, without being unreasonably curved, such a road would be better than an undulating one: because the locomotive engines would require to be transported less frequently over the ground, to convey a certain quantity of goorls on such a road, although the expenditure of steam for conveying the train, independent of the locomotive, would be as great on the level road as on the undulating one. A perfectly level road, however, is impracticable in most parts of the country, except at an expense far exceeding the value of the benefit gained. Hence, it is probable that few roads will hereafter be made, without ascents and descents, in some parts, at the rate of forty to fifty feet per mile.

Such ascents being admitted in some parts of the road, the locomotives will take no greater trains than they can draw up those ascents. Hence, it will be useless to make excavations, embankments, and curvatures, to avoid other ascents of the same grade.

A locomotive will take a train up an ascent of twenty-one feet to the mile, and down a descent of the same length and grade, with precisely the same expenditure of steam, if it be constantly used, as would be required to take the same train over the same distance, on a perfect level. If the train were such as to require for drawing it on a level, a pressure of steam on the piston of thirty-six pounds to the inch, above the atmosphere, then on the ascent of twenty-one feet per mile, it would require sixty-three pounds per inch, and on the descent of the same grade, nine pounds per inch, making the average thirty-six pounds or the same as on the level.-Thus, $63+7=$ $72 \div 2=36$ pounds.

If, however, the road were composed of alternate ascents and descents, at the rate of from thirty to forty feet per mile, with but short levels between them, the engine would transwort such train as it could draw on the road, 